\title{
High Dynamic Range (HDR) images of radiographies: modern digital replacement of negatoscopes?
}

\author{
Luís Bravo Pereira
}

\begin{abstract}
With this paper we are presenting a new promising approach to digitalization of radiographic image in film, using common photographic cameras as device to digitalize with different levels of exposure (allowing, in some cases, to read information from the darker/denser areas of the image) and combining those images with the new technique of High Dynamic Range (HDR) imaging, increasing this way the exposure latitude of the final image. This new approach is possible today because the most recent generations of image treatment software present this new feature. Examples of software presenting this tool are the market leader Adobe Photoshop (presenting this HDR capacity since CS2 version) or the most HDR specialized Photomatix, among others. The resulting images seem to show in some cases more interesting results than the single pass digitalization of images, with or without post-processing improvement, and can in some cases be a good alternative to the use of negatoscopes on the exam of radiographies.
\end{abstract}

\section{Keywords}

Radiography, HDR, negatoscope, Photoshop, Photomatix.

\section{Resumo}

Neste artigo apresentamos uma aproximação promissora à digitalização de imagem radiográfica em filme, através da utilização de máquinas fotográficas comuns enquanto mecanismos que permitem a digitalização com diferentes níveis de exposição (permitindo, em alguns casos, ler informação a partir das áreas mais escuras e densas da imagem) e combinando estas imagens com novas técnicas de High Dynamic Range (HDR), aumentando desta forma a latitude de exposição do resultado final. Esta nova abordagem é actualmente possível devido às mais recentes gerações de software para tratamento de imagem que presentemente utilizamos. Como exemplos de software que possuem esta ferramenta podemos apontar o líder de mercado Adobe Photoshop (que apresenta esta capacidade em HDR desde a versão CS2) ou o mais especializado em termos de HDR, Photomatix, entre outros. As imagens finais apresentam em alguns casos resultados mais interessantes do que a simples digitalização de imagem, com ou sem processamento posterior e pode, em alguns casos, ser uma boa alternativa ao uso de negatoscópios no exame de radiografias. 
High Dynamic Range (HDR) images of radiographies: modern digital replacement of negatoscopes?

Luís Bravo Pereira

\section{Palavras-chave}

Radiografia, HDR, negatoscópios, Photoshop, Photomatix.

\section{Resumen}

Con este estudio presentamos una nueva aproximación a la digitalización de las imágenes radiográficas en película, usando cámaras fotográficas comunes como mecanismos para digitalizar con diferentes niveles de exposición (permitiendo, en algunos casos, leer la información de las áreas oscuras/más densas de la imagen) y combinando aquellas imágenes con las nuevas técnicas de High Dynamic Range (HDR), incrementando de este modo la latitud de la exposición de la imagen final. Esta nueva aproximación es posible hoy en día debido a las más recientes generaciones de software para el tratamiento de imágenes. Como ejemplos de software que ofrecen esta herramienta está el líder del mercado Adobe Photoshop (presentando esta capacidad de HDR desde la versión CS2) o el más especializado HDR Photomatix, entre otros. Las imágenes obtenidas parecen mostrar en algunos casos resultados más interesantes que las del simple paso de digitalización de imágenes, con o sin implementar el posterior procesamiento, y pueden, en algunos casos, ser una buena alternativa al uso de negatoscopios en el examen de radiografías.

\section{Palabras clave}

Radiografía, HDR, negatoscopio, Photoshop, Photomatix.

\section{Introduction}

One problem with traditional film radiography of works of art is the large difference in density of the images between areas of different radiopacity, principally with three dimensional works, like wood sculptures. To be possible to scientists, historians and conservators analyze radiography with all their differences in density, usually it is necessary to use negatoscopes, a special type of light-box that have included a special illumination system that allows the user to control the power of background light. But those systems are rare to find, they are size limited and usually expensive. Even like that none of them gives a good reading of denser (darker) areas simultaneously with less denser (lighter) areas of a radiography!

Besides being commonly smaller than the total area of the X-rayed image, negatoscopes do not allow a general perception of the entire work of art with is entire tonal range.

In the eighties this technological limit was turnaround with the use of special equipment like the Logetronic radiography (Schoute et al., 1986) and, more recently, with "digital enhancement" with computers. 
High Dynamic Range (HDR) images of radiographies: modern digital replacement of negatoscopes?

Luís Bravo Pereira

\section{Digital enhancement with computers: advantages and risks}

Recently, with the advent of computers and scanner devices, it was possible to digitalize a radiography and improve the contrast/brightness of the image, improving the readability of the information but usually the darker areas (corresponding to more dense areas) or the lighter ones do not show their full information simultaneously.

Sometimes the digital enhancement can also "destroy" the readability of some areas of the image or create artefacts, as shown when comparing the following Figures 1 and 2 of a radiography made by the author (followed by a digital treatment of the image, on Figure 2 ).

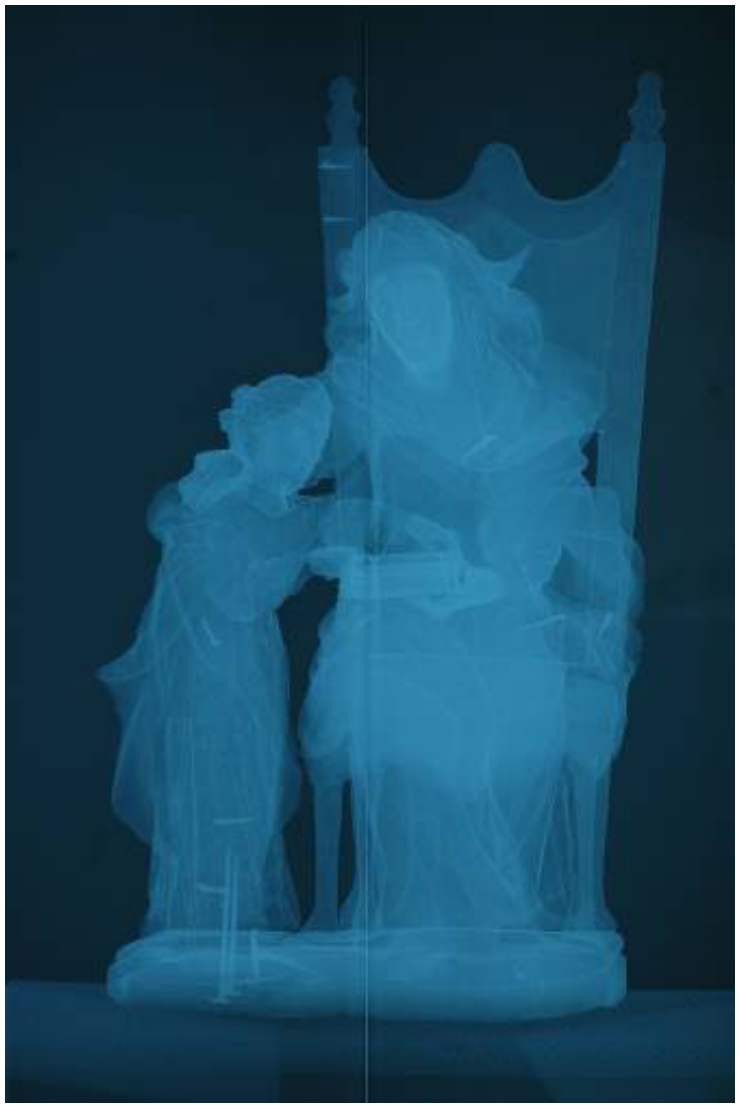

Figure 1 - Example of an well exposed radiography of an wooden sculpture, ("St. a Ana e N. a Sr.a", possibly from XVIII century) digitalized with a DSLR camera (Nikon D70), without digital treatment (only converted from RAW to JPG file).

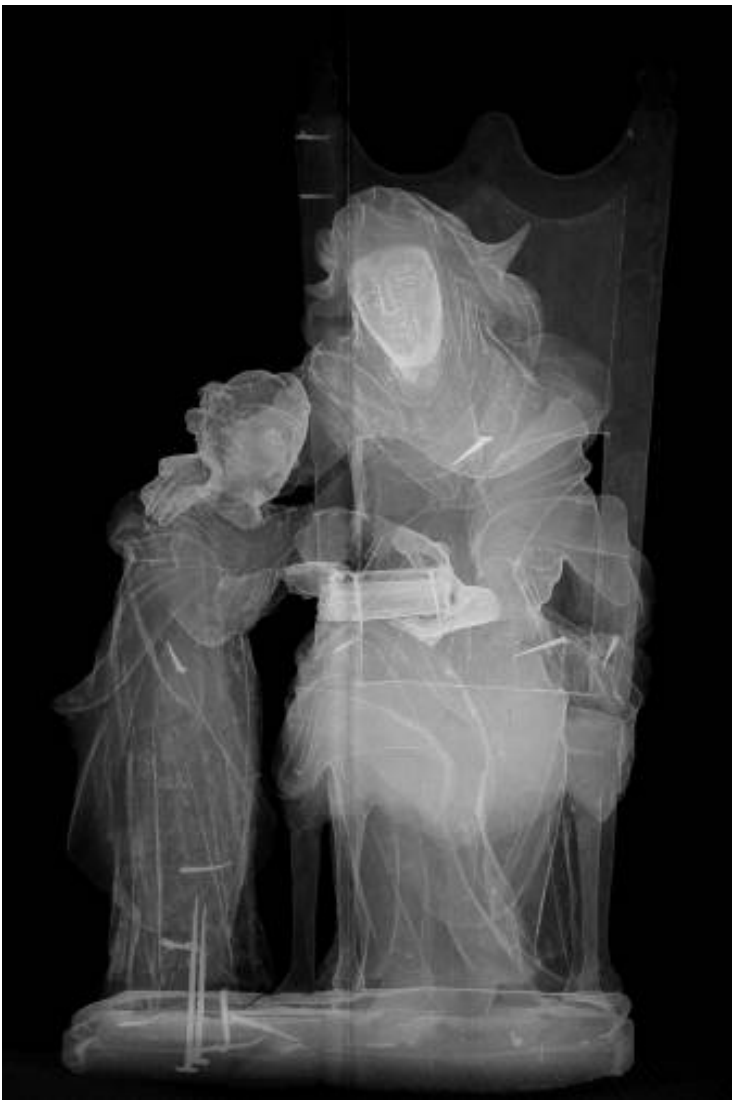

Figure 2 - the same image from Fig. 1 but digitally enhanced with Photoshop, showing the final result overall better details reading. However, some information was lost, on the thinner parts of the sculpture (compare with fig.1).

Image treatment data - Image treated with Photoshop:

- Converted from RAW file

- Colour desaturated

- Curves applied (to improve overall contrast; "levels" could be used instead)

- Unsharp mask applied 
High Dynamic Range (HDR) images of radiographies: modern digital replacement of negatoscopes?

Luís Bravo Pereira

\section{Exposure latitude, Dynamic Range and bit depth}

To better understand the technique of making High Dynamic Range (HDR) images when photographing radiographies and how this allows overcoming the limits of one single exposure photograph, we will explain briefly three concepts necessary to understand HDR: Exposure latitude, Dynamic Range and Bit depth.

\section{Exposure latitude:}

This is a concept that comes from film photography; it tell us how many Exposure Values (EVs or photographic "stops") can be registered showing detail on a type of film. For example, the traditional slide or transparency film usually presents an exposure latitude of 3 EVs, usually $1 \frac{1}{2} 2$ each side of "correct exposure"; on the other hand Negative film usually present 5 stops of exposure latitude, 21/2 each side of "correct exposure".

If the necessary exposure range is wider than the latitude of the film, the information on dark areas stay black, or white on brighter areas, but in both cases without distinguishable information (no visible details) on it.

With digital photography, the term "exposure latitude" is less used to describe the sensor characteristics than other two related parameters: "Dynamic Range" and "Bit Depth", explained bellow:

\section{Dynamic Range:}

The capacity of a scanner or digital camera to digitalize different densities of an image usually is mentioned by the respective device maker on the specifications of the equipment. The density is measured with a logarithmic scale:

$D=0$ : minimum value (Dmin), corresponding to pure white tone a device can represent; $D=4$ : maximum value (Dmax)), corresponding to pure black tone a device can represent. The difference between Dmax and Dmin is what is known as "Dynamic Range"; so in practical terms Dynamic Range is the range of tones a device can represent. Example: a scanner with Dmax=3.2 and Dmin=0.1, gives a final Dynamic Range of 3.1 (3.2 - $0.1=$ 3.1)

\section{Bit Depth:}

The quantity of information (measured in Bit) stored in all channels of colour to represent the tones is known as "Bit Depth"; Example: if a RGB camera or scanner presents Bit Depth of 42 bit, that means they have 14 bit of information for each colour channel (Red channel, Green channel or Blue channel): 14 bit $\times 3=42$ bit

42 bit is the maximum Bit Depth of currently commercialized DSLR cameras.

Dynamic Range and Bit Depth are interrelated: an higher Bit Depth on a device usually means that it can have an wider Dynamic Range too.

So how Dynamic Range and Bit Depth relation works? 
High Dynamic Range (HDR) images of radiographies: modern digital replacement of negatoscopes?

Luís Bravo Pereira

There is a very good metaphor that helps to better explain how this interrelation works (Blatner et al., 1998), explained on the next Figure (Fig. 3).
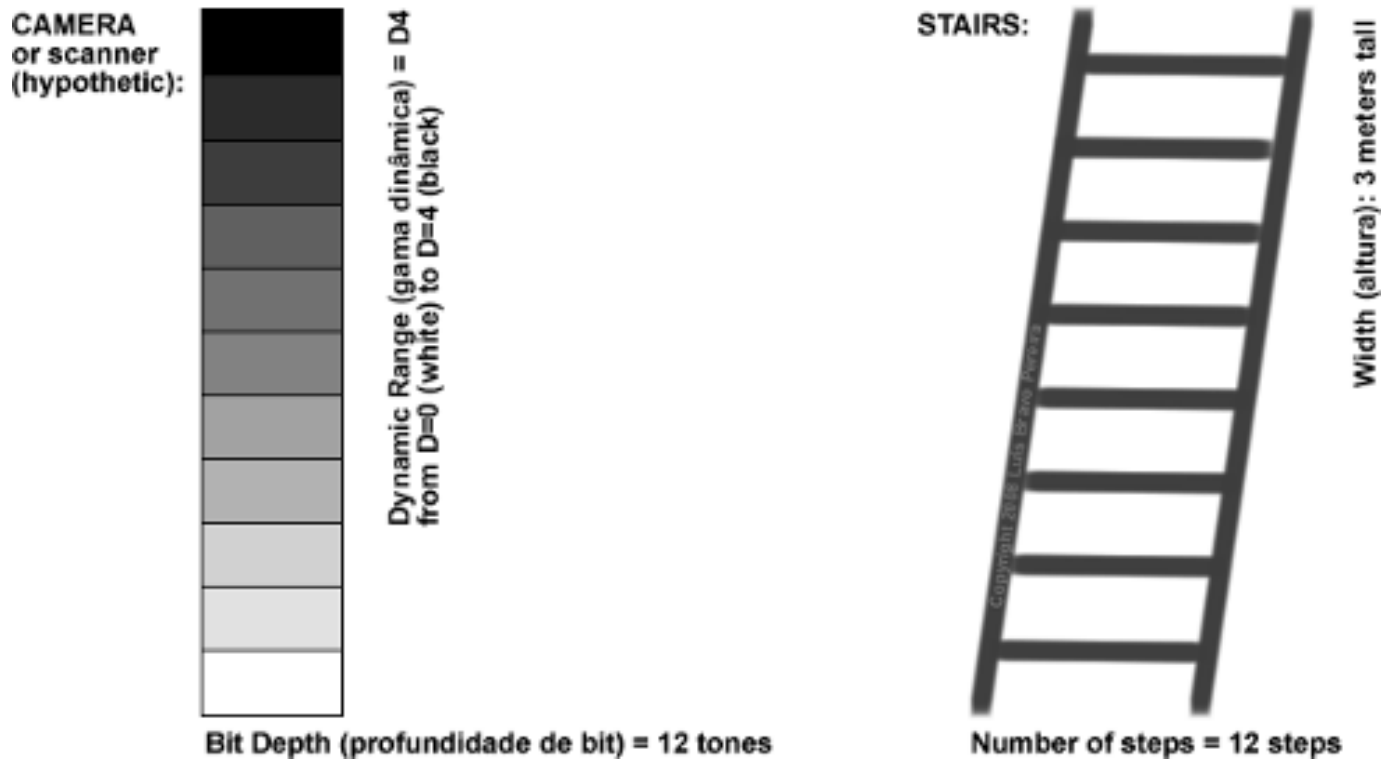

Figure 3 - The Blatner et al. "Real World Scanning and Half Tones Book" metaphor for digital devices: the stairs!

Dynamic Range - the "range" of the stairs (maximum length, for ex.: 3 meters):

Bit Depth - the quantity of steps of the stairs (for example, 12 steps)

In a stairs it is important not only the length or how high the stairs can reach but also the number of steps. Both characteristics are important and usually interrelated: frequently the stairs with a bigger number of steps can also reach a higher height, but this is not mandatory and some stairs can have a long height with a small number of steps or vice versa.

If Dynamic Range is the "height" or range of tones a device can reach, it is also important the Bit Depth or the number of intermediate tones this device can represent. As we have already said before, both characteristics are interrelated and both are important.

\section{HDR images}

One way to surpass the physical limit of the Dynamic Range of a device is to join the information of different images (taken with different exposures), extending that way the final Dynamic Range and Bit Depth: this is what is called High Dynamic Range (HDR) imaging. On the following figures (Fig. 4 and 5) we show an example of maybe the most common use of an HDR image: applied to a landscape (taken by the author at Ordesa National Park, in the Spanish Pyrenees): 
High Dynamic Range (HDR) images of radiographies:
modern digital replacement of negatoscopes?

Luís Bravo Pereira
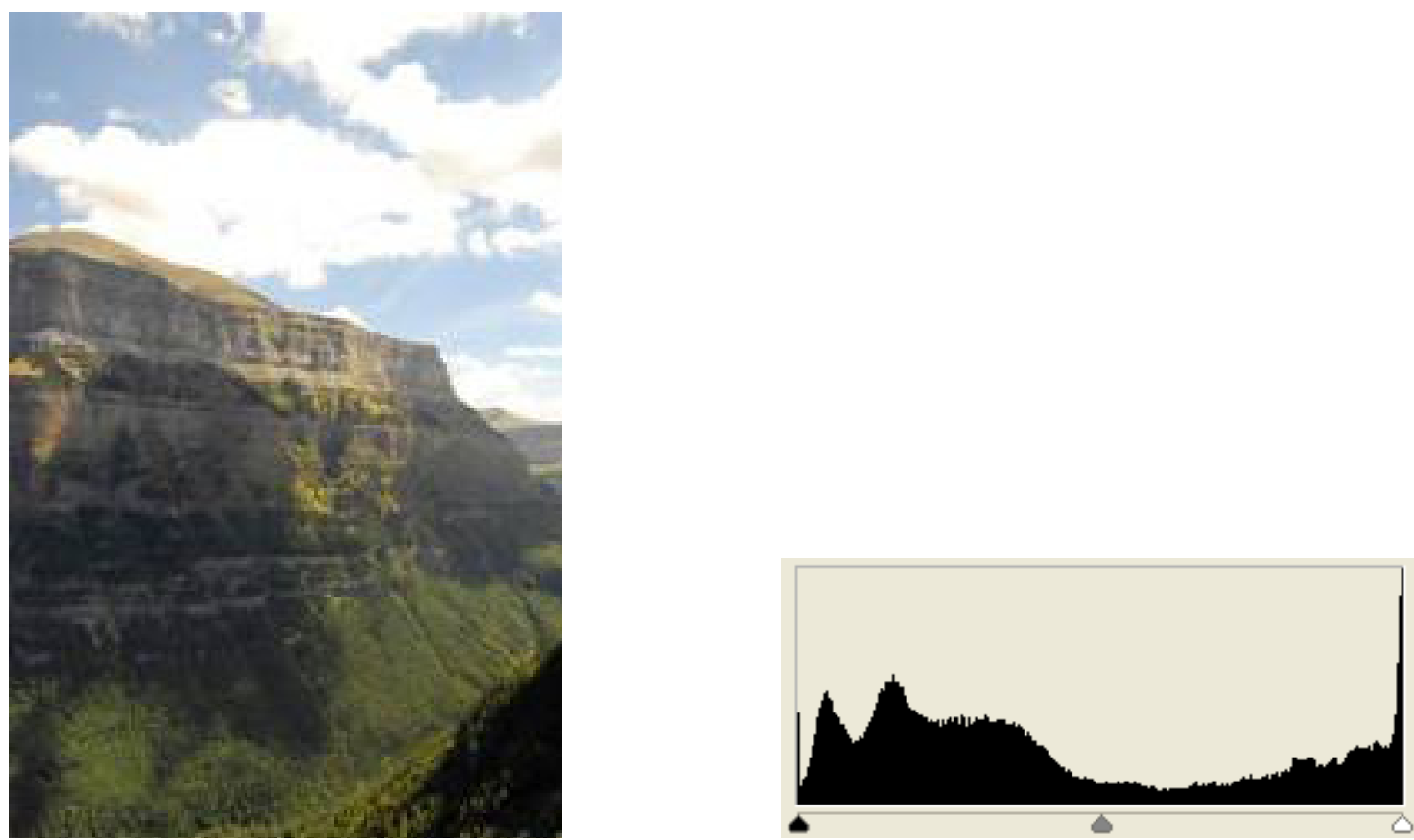

Figure 4 - Normal camera exposure: we can appreciate the lost of details on highlights and deep shadows.

On the histogram it is visible the strong clipped areas representing the lost of detail on highlight (right side of the graphic) and shadows (left side of the graphic).
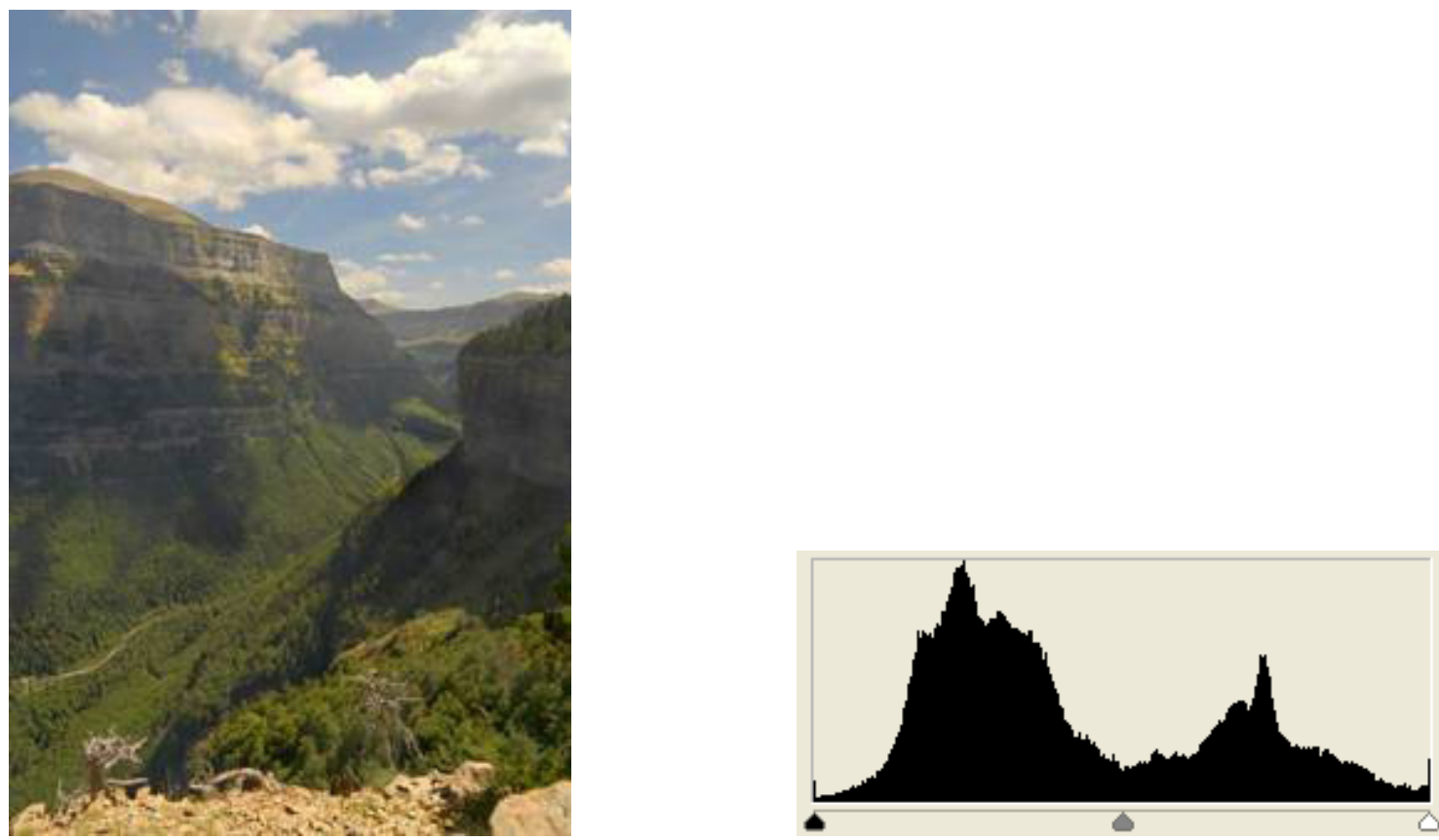

Figure 5 - HDR composite resulting from 9 photos with different exposures (1 stop bracket), produced with Photoshop: now we have details on shadows, middle tones and highlights!

Shooting data - Nikon D200 camera, Nikkor 18-200mm lens, aperture priority auto-exposure, 1 EV step 9 frames autobracketing, fast continuous shooting at 5 frames per second to avoid clouds and trees movement.

Camera mounted on tripod and triggered with remote cable release. 
High Dynamic Range (HDR) images of radiographies: modern digital replacement of negatoscopes?

Luís Bravo Pereira

This technique it is only possible to apply to static objects; fortunately this is the case of Works of Art and radiographies!

With HDR (at least with current state of the Art), we lose colour representation accuracy; this can be a problem to represent works of art, but with monochromatic radiographic representation colour is not a problem!

\section{Softwares for HDR}

Adobe Photoshop (CS2 version or greater): in our opinion, the best for use with radiographies; it is widely used by the serious photographers, so usually they already have it and are familiar with his interface;

HDRSoft Photomatix Pro, maybe easier and more useful for landscape photography, but on our experience not so satisfying for X-ray HDR images; but it is a question of user preference, not a "technical conclusion".

In the present paper we have used the Photoshop CS2 "Merge to HDR" function to present our HDR results.

\section{HDR on a radiography: a practical case}

For this experience we have used the side radiography of an wooden sculpture (S. Estêvão, polycrom. Wood, possibly from XVIII century). On this radiography it was difficult to have a good reading of thinner details of the sculpture (using a lightbox, not a true negatoscope). We have done the digitalization of this radiography with a DSLR (Nikon D70), 8 exposures with 1 stop bracket steps varying the shutter time, captured on Nikon's NEF Raw files.

The HDR was built using the resulting images and combining them with the Adobe Photoshop CS2 "Merge to HDR" automation.

On the figures we can appreciate the side radiography of the mentioned wooden sculpture, were is difficult to have a good reading of thinner details of the sculpture (ex.: nose, air,...) on the most common "average exposure" single photography (Fig.6). Overexposed digitalization of the same radiography it is shown on the Fig. 7.

In that case, the thinner parts of the sculpture are now visible, revealing that those details were registered on film. Unfortunately, now we lose the highlight details (corresponding to thicker sculpture parts) at the same time! 

High Dynamic Range (HDR) images of radiographies:
modern digital replacement of negatoscopes?

Luís Bravo Pereira

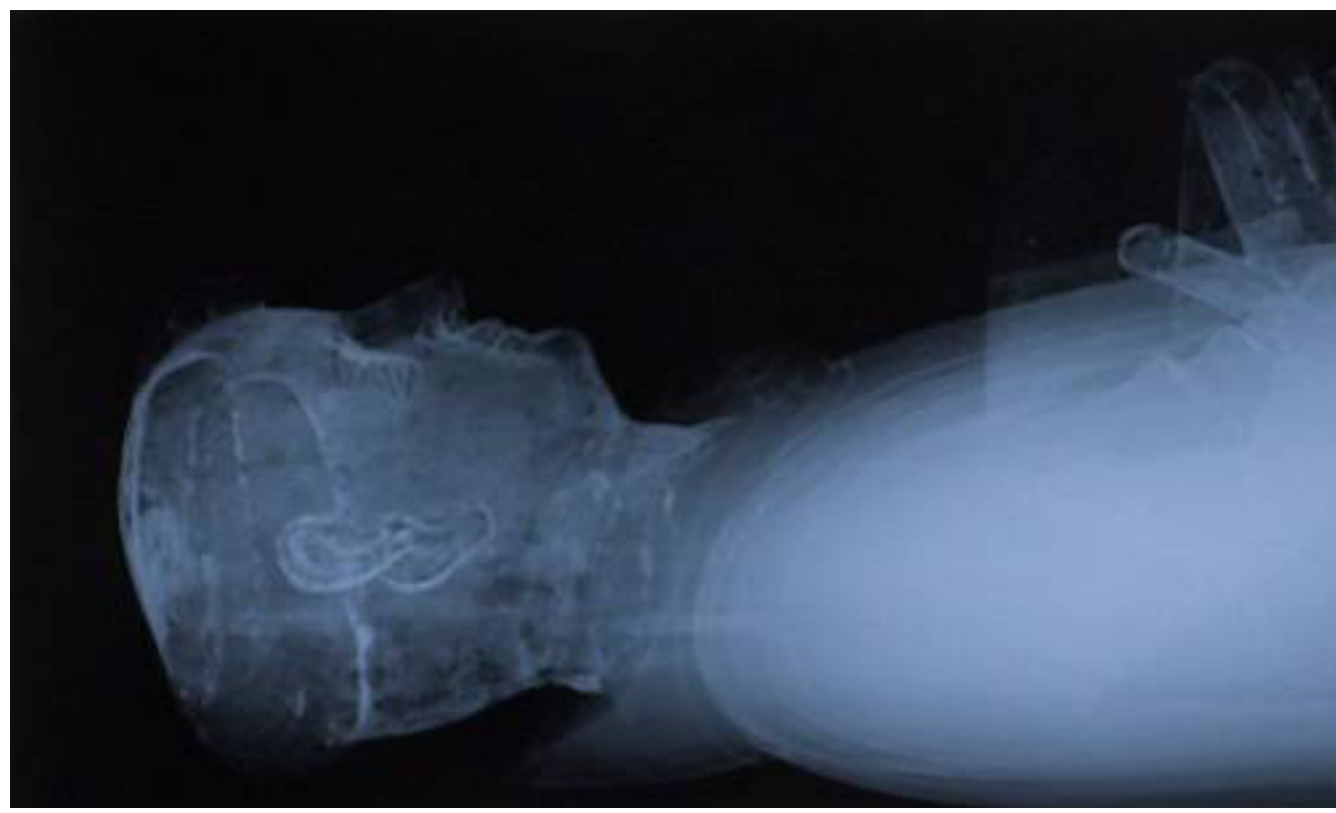

Figure 6 - digital photography of a film radiography

Radiography data - Portable YXLON X-ray ampoule, model SMART 160E/ 0,4. with additional Al filter removed. Radiographic film Agfa ref. 3JSLY D, D7. Exposure made with the film at 3 meters from the X-ray source, during 60 seconds at $75 \mathrm{kV}, 6 \mathrm{~mA}$.

Digitalization data - Radiography mounted on a lightbox and photographed with a Nikon D70 camera with Micro Nikkor $60 \mathrm{~mm} / \mathrm{f} 2.8$ lens, image captured at 1/20 sec., f/8, iso 200, NEF Raw file.

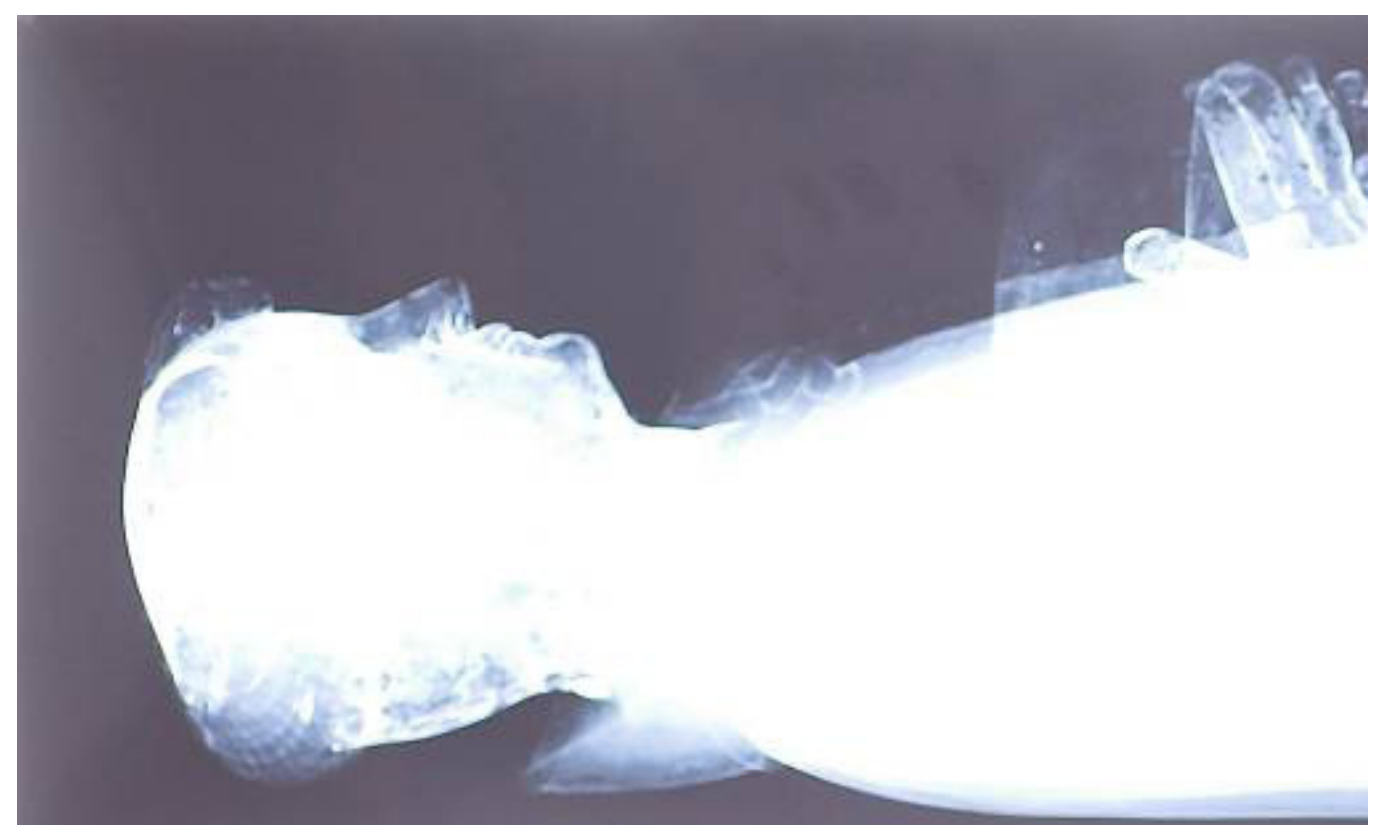

Figure 7: over-exposed digital photography of a film radiography

Radiography data - It is the same radiography that was described on Fig.6. (75 kV - $6 \mathrm{~mA}-3 \mathrm{~m}-1 \mathrm{~min}$.). Digitalization data - Radiography mounted on a lightbox and photographed with a Nikon D70 camera with Micro Nikkor 60mm/f2.8 lens, image captured at 0,77 sec., f/8, iso 200, NEF Raw file. 
High Dynamic Range (HDR) images of radiographies: modern digital replacement of negatoscopes?

Luís Bravo Pereira

We have taken a sequence of eight photos of the radiography, with a difference of $1 \mathrm{EV}$ exposure between them.

The attributes for these photos are:

In common:

- Radiography mounted on a lightbox;

- Radiography photographed with a Nikon D70 camera

- Micro Nikkor $60 \mathrm{~mm} / \mathrm{f2} 2.8$ lens

- Image captured at $f / 8$, iso 200, NEF Raw file.

Varying only the exposure with the shutter:

- $1 / 80 \mathrm{sec}$.

- $1 / 40 \mathrm{sec}$.

- $1 / 20 \mathrm{sec}$.

- $1 / 10 \mathrm{sec}$.

- $1 / 5 \mathrm{sec}$.

- $1 / 2 \mathrm{sec}$.

- $1.6 \mathrm{sec}$.

- $3 \mathrm{sec}$.

Combining the resulting eight photos with the "merge to HDR" automation on the Photoshop, interface window of this Photoshop tool is shown on the figure 8:

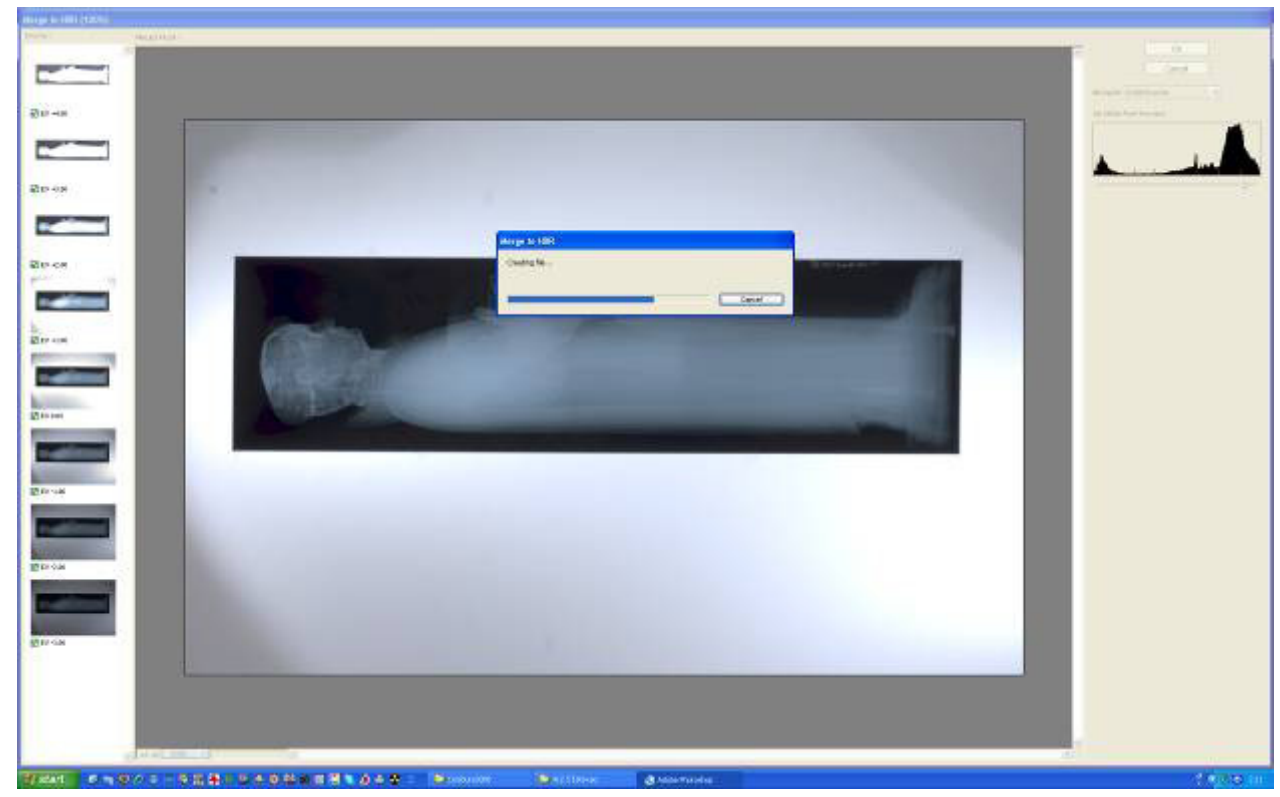

Figure 8: screen capture showing the appearance of "Merge to HDR" automation on Photoshop, during the process of combining the selected 8 photos. 
High Dynamic Range (HDR) images of radiographies: modern digital replacement of negatoscopes?

Luís Bravo Pereira

The resulting HDR composite image, made from eight different photos, presents 32 bit per channel Bit Depth (total 96 bit RGB!). The dynamic Range it is now so wide that it is impossible to represent on a common computer screen. It shows a bizzar look and at a first appreciation disappointing, as shown on figure 9.

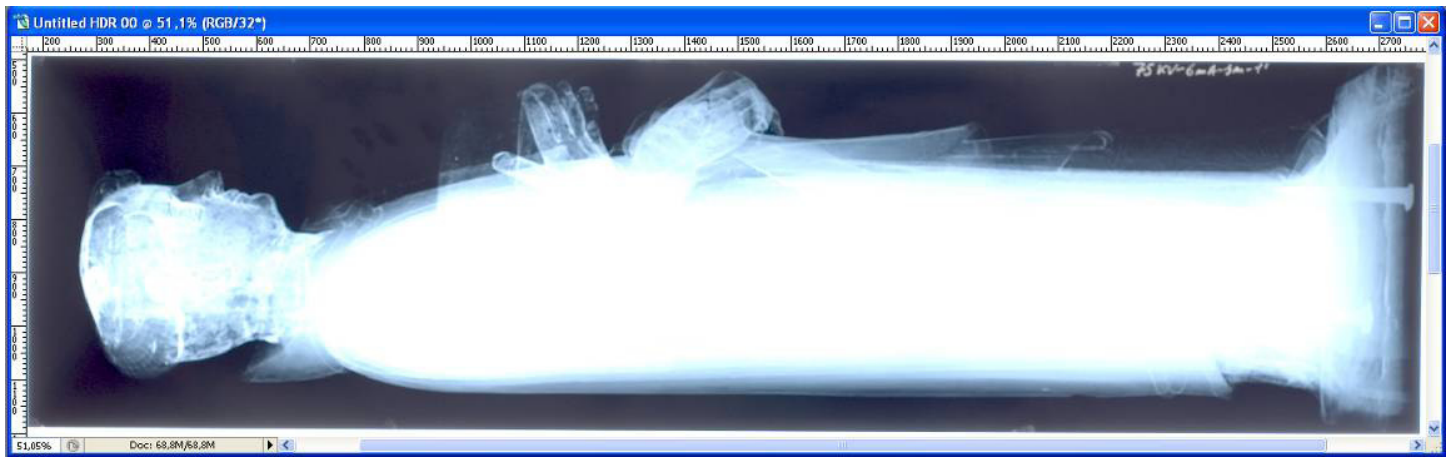

Figure 9: screen capture of the resulting 96 bit HDR composite, impossible to show all his Dynamic Range in tonalities on a 24 bit limited computer screen.

So to be useful we need to convert the resulting 96 bit image to a more frequent (and screen compatible) 24 bit RGB image ( 8 bit per channel image).

With the image opened on Photoshop, we can perform a conversion from 32 bit per channel to 8 bit per channel on the following menu/options: "Image>Mode> 8 bit/ channel".

Another interface window appears asking to choose the conversion method to reduce from 32 to 8 bit; we have used the "Local Adaptation" method, working with curves on the histogram, searching for the best overall visualization of detail.

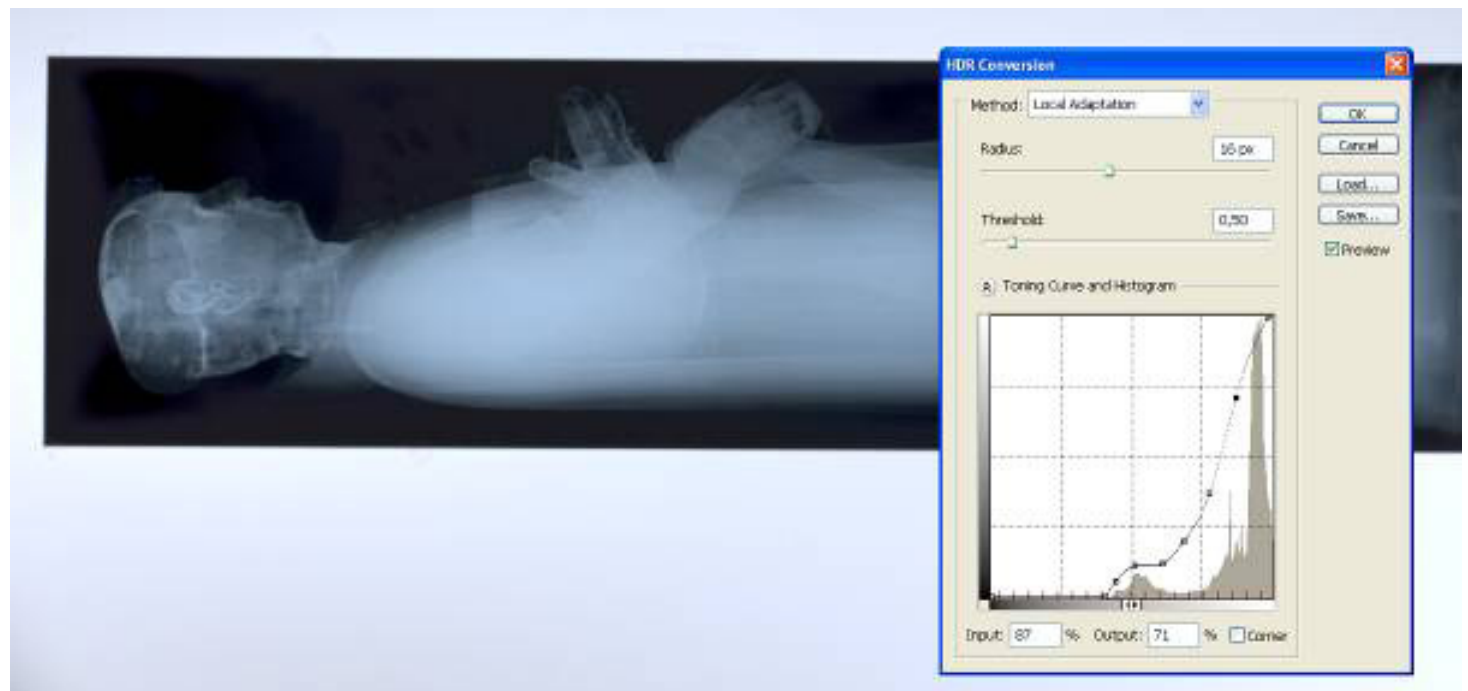

Figure 10: screen capture of the "Local adaptation" conversion window, were it is possible to perform a visual enhancing using the histogram and curves. 
High Dynamic Range (HDR) images of radiographies: modern digital replacement of negatoscopes?

Luís Bravo Pereira

Completing the conversion, now we can save the final resulting image file as a 24 bit TIFF or other convenient image file.

On the following image finally we can compare a detail of the radiography before (figure 6 ) and after HDR conversion (figure 11). The red arrows are showing areas were we can observe detail when it was almost invisible in a single shot photography (figure 6).

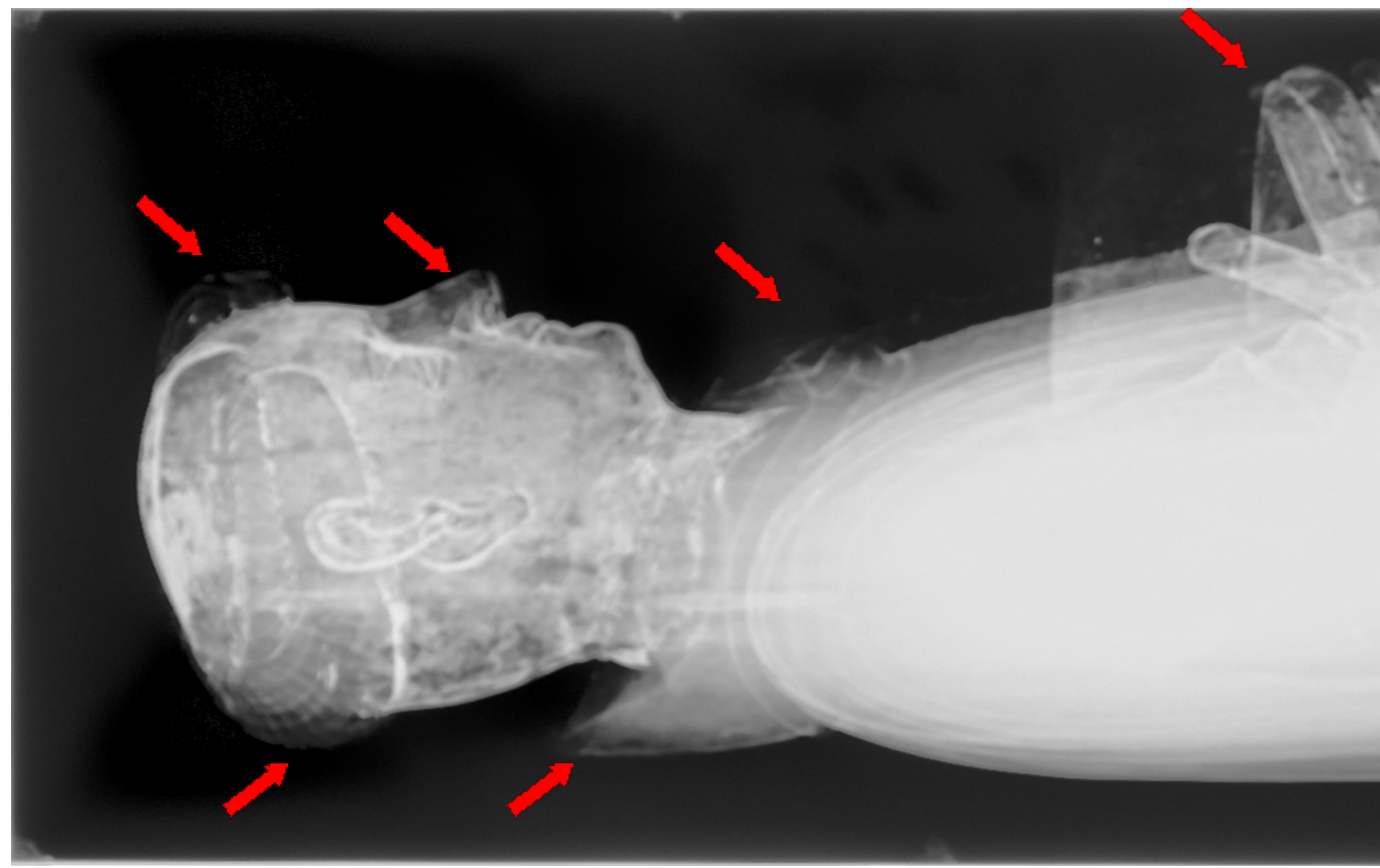

Figure 11 - detail of an HDR composite of a radiography

Radiography data - Portable YXLON X-ray ampoule, model SMART 160E/ 0,4. with additional Al filter removed. Radiographic film Agfa ref. 3JSLY D, D7. Exposure made with the film at 3 meters from the X-ray source, during 60 seconds at $75 \mathrm{kV}, 6 \mathrm{~mA}$.

HDR data - Radiography mounted on a lightbox and photographed with a Nikon D70 camera with Micro Nikkor $60 \mathrm{~mm} / \mathrm{f} 2.8$ lens, image captured at f/8, iso 200, NEF Raw file;

HDR image made with Photoshop CS2, merging these 8 photos taken with 1 stop exposure step (1/80 sec., $1 / 40 \mathrm{sec} ., 1 / 20 \mathrm{sec} ., 1 / 10 \mathrm{sec} ., 1 / 5 \mathrm{sec} ., 1 / 2 \mathrm{sec} ., 1.6 \mathrm{sec} ., 3 \mathrm{sec} \mathrm{sec}$.); the final result was converted to 8 bit/ channel (24 bit) and desaturated to monochromatic result.

\section{Conclusion}

With this experience we believe we have proved that, at least in some cases, we can replace with advantages the traditional negatoscope by a virtual "lightbox" using High Dynamic Range imaging technologies. It is possible to have a final image representing on the same single image all the available details in high contrast radiographic images, such is the case in sculptures side radiographies. This technique presents also the advantage of being more affordable to the majority of potential users and usually any photo studio already has the necessary tools: a lightbox, a digital camera and postproduction software with HDR function, like the Adobe Photoshop (CS2 version or greater). 
High Dynamic Range (HDR) images of radiographies: modern digital replacement of negatoscopes?

Luís Bravo Pereira

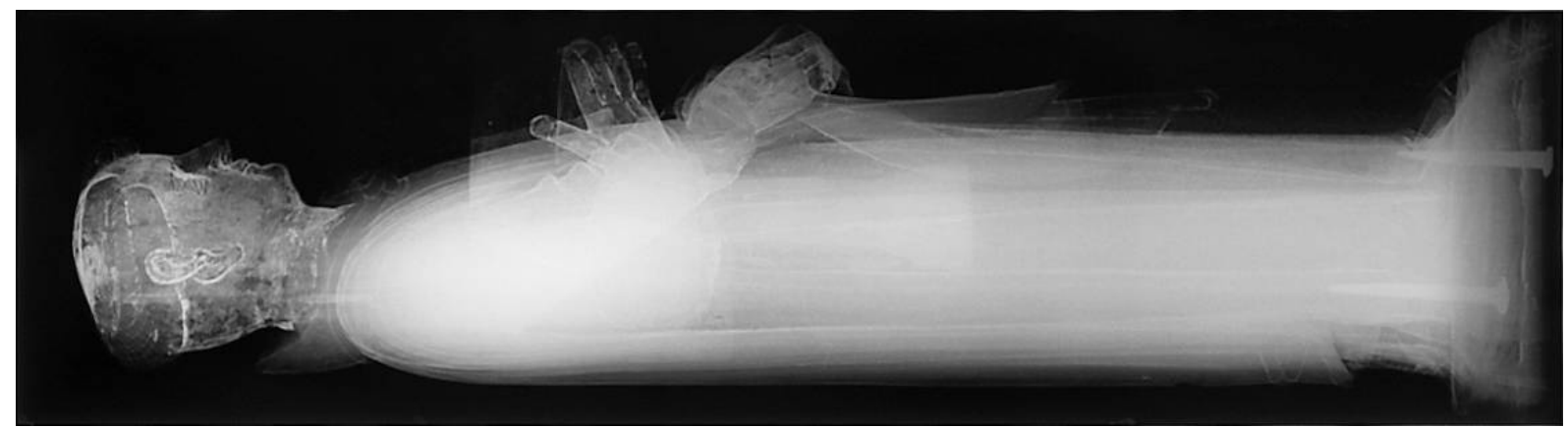

Figure 12.a) - Complete radiography image without HDR (normal single shot exposure photo);

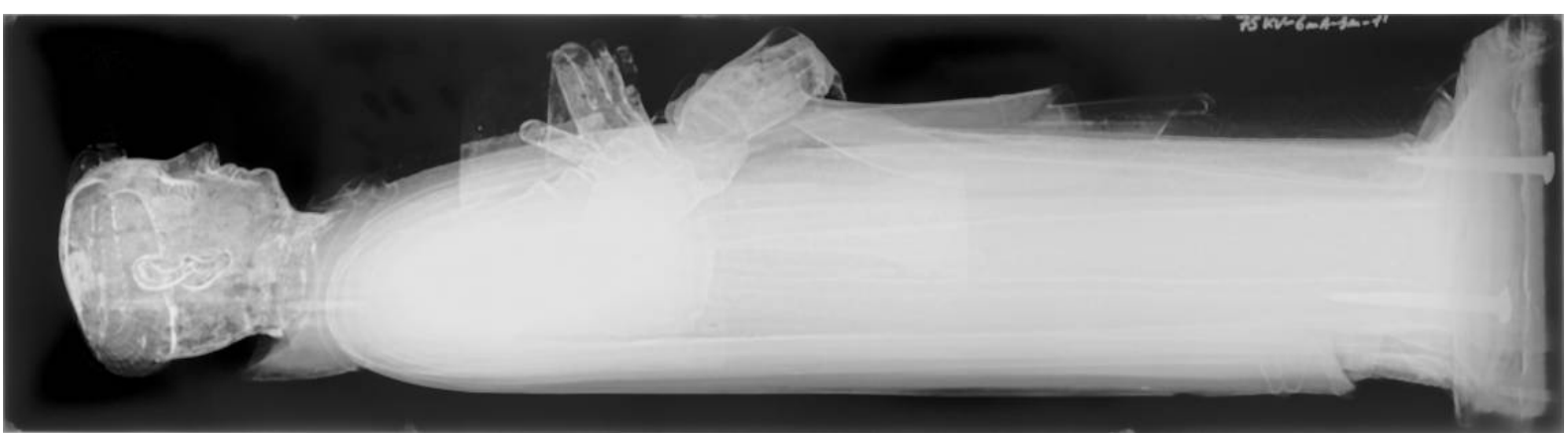

Figure 12.b) - HDR final composite resulting of 8 pictures (with 1 stop of difference for exposure) merged. Read the text and previous figures for technical details.

\section{References}

[1] ALDROVANDI, Alfredo; PICOLLO, Marcello. (2001) Metodi di documentazione e indagini non invasive sui dipinti. Padova: Il Prato.

[2] CASTELLANO, Alfredo; QUARTA, Stefano. «Le Tecniche radiografiche per I'archeometria.», In CASTELLANO, Alfredo; MARTINI, Marco; SIBILIA, Emanuela, (2002) coord.- Elementi de Archaeometria. Metodi fisici per i beni culturali. Milano: ESEA, pp. 131-153.

[3] SCHOUTE, Rogier Van; VEROUGSTAETE, Hélène. «Radiography», In VAN SCHOUTTE, Roger; VEROUGSTRAETE-MARCQ, Hélène, (1986) coord. - Scientific Examination of Ease Paintings. Strasbourg: Council of Europe:, PACT 13, pp. 131-153.

[4] BLATNER, David; FLEISHMAN, Glenn; ROTH, Steve (1998). Real World Scanning and Halftones. 2nd Ed. Berkeley: Peachpit Press, pp. 13-16.

\section{Acknowledgements}

- To the Universidade Católica Portuguesa (Centro de Cons. e Restauro and CITAR), for the permission to use the images and radiographies presented here. 
High Dynamic Range (HDR) images of radiographies: modern digital replacement of negatoscopes?

Luís Bravo Pereira

- To the ownwers of the works of art showed on the examples presented here: the "Museu de Santa Maria de Lamas", owner of "S. Estêvão" sculpture; "Igreja de Santa Maria de Airães", owner of "Sta Ana e N. Sra" sculpture.

- This research was also supported in part by "Fundação para a Ciência e Tecnologia" training grant SFRH / BD / 39192 / 2007.

\section{Biographical notes}

Luís Bravo Pereira is an Assistant at Universidade Católica Portuguesa (U.C.P.) - Escola das Artes - since 2003, technical responsible for the photographic and radiographic studio at the U.C.P. Restoration Center; presently it is developing his PhD research and thesis on Multispectral imaging applied to works of Art. 